\title{
A Freight Mode Choice Analysis Using a Binary Logit Model and GIS: The Case of Cereal Grains Transportation in the United States
}

\author{
Guoqiang Shen, Jiahui Wang \\ Division of Regional and City Planning, College of Architecture, School of Industrial Engineering \\ College of Engineering, The University of Oklahoma, Norman, USA \\ Email: guoqiangs@ou.edu
}

Received January 4, 2012; revised February 23, 2012; accepted March 14, 2012

\begin{abstract}
Mode choice is important in shipping commodities efficiently. This paper develops a binary logit model and a regression model to study the cereal grains movement by truck and rail in the United States using the publically available Freight Analysis Framework $\left(\mathrm{FAF}^{2.2}\right)$ database and US highway and networks and TransCAD, a geographic information system with strong transportation modeling capabilities. The binary logit model and the regression model both use the same set of generic variables, including mode split probability, commodity weight, value, network travel time, and fuel cost. The results show that both the binary logit and regression models perform well for cereal grains transportation in the United States, with the binary logit model yielding overall better estimates with respect to the observed truck and rail mode splits. The two models can be used to study other commodities between two modes and may produce better results if more mode specific variables are used.
\end{abstract}

Keywords: Binary Logit; Regression; Freight; Mode Choice; Cereal Grains

\section{Introduction}

Freight transportation in general refers to the aggregated movement of goods from one location to another. Today, most goods worldwide are transported on multi-modal networks involving waterways, railways, highways, airways, and intermodal facilities. In the United States, the highway network carries the majority of the total freight. Rail is mostly used in shipping bulk and heavy commodities over longer distances. According to the 1997 and 2002 Commodity Flow Surveys, conducted by the US Bureau of the Census, about $60 \%$ of the total freight in 1997 and $70 \%$ in 2002 was shipped by the US highway network with the rail comes in as the second [1]. The splits of tonnage by common modes are listed in Table 1 [2].

Freight transportation is vital to the US and world economy. In 2002, the US transportation system moved 53 million tons of freight worth of $\$ 36$ million each day. It is expected that there will be an increase of $67 \%$ in domestic shipping and $87 \%$ in international shipping over the next 20 years in US [3]. Freight is also an important factor for national and local decisions on public policies, such as infrastructure, investment, and security. For example, Intermodal Surface Transportation Efficiency Act (ISTEA) of 1991 required all Metropolitan
Planning Organizations and Planning agencies to include freight transportation issues in state and metropolitan transportation plans [4]. This was further continued with Transportation Equity Act for the $21^{\text {st }}$ Century (TEA-21) and the most recent Safe, Accountable, Flexible, Efficient Transportation Equity Act (SAFETEA-LU) of 2005 [5].

The cereal grains logistics is an important element of overall freight movement in the US, particularly for agriculture crops and related products that demand for significant transportation services involving movement of grains from their production sites to storage points, and then to domestic and export markets. Truck, train, and barge compete and complement one another in moving cereal grains. During the 1978-2004 period, cereal grains shipments increased $157 \%$ by truck, $31 \%$ by barge, and $16 \%$ by rail [6]. A US Department of Agriculture report [7] on modal shares of grains transportation indicates that truck and rail are the two predominant modes (i.e., 96\%+) for domestic movement of cereal grains, with barge being mainly for cereal grains import and export involving water shipment [8]. However, these studies, plus a few existing reports on cereal grains (i.e., [9]), are mostly based upon data collections or surveys, hence descriptive in nature without much prescriptive capability. The 
Table 1. Mode splits by total freight weight (million tons) in the US, 2002 and 2007.

\begin{tabular}{|c|c|c|c|c|c|c|c|c|}
\hline & \multicolumn{4}{|c|}{2002} & \multicolumn{4}{|c|}{2007} \\
\hline & Total & Domestic & Exports & Imports & Total & Domestic & Exports & Imports \\
\hline Total & 19,328 & 17,670 & 525 & 1133 & 21,225 & 19,268 & 619 & 1338 \\
\hline Truck & 11,539 & 11,336 & 106 & 97 & 12,896 & 12,691 & 107 & 97 \\
\hline Rail & 1,879 & 1769 & 32 & 78 & 2030 & 1872 & 65 & 92 \\
\hline Water & 701 & 595 & 62 & 44 & 689 & 575 & 57 & 57 \\
\hline Air, air \& truck & 11 & 3 & 3 & 5 & 14 & 4 & 4 & 6 \\
\hline Intermodal & 1292 & 196 & 317 & 780 & 1505 & 191 & 379 & 935 \\
\hline Pipeline \& unknown & 3905 & 3772 & 4 & 130 & 4091 & 3934 & 6 & 151 \\
\hline
\end{tabular}

Source: US Department of Transportation, Federal Highway Administration, 2008.

http://ops.fhwa.dot.gov/freight/freight_analysis/nat_freight_stats/docs/08factsfigures/index.htm

literature also points out that the mode choice for shipping cereal grains varies considerably by distance, speed, cost, and other variables. Typically, however, trucks are used primarily for short haul distances while railroads have a cost advantage for cereal grains over a longer distance.

This paper develops a binary logit model to estimate the mode splits for cereal grains movement by truck and rail in the US The paper starts with a concise literature review on freight movement and model choice in Section 2. In Section 3, a binary logit model is developed for truck and rail. The results from the logit model are compared with those observed and from a common linear regression model. Here, the regression and logit model use the same set of generic variables, hence providing a base for comparison. Relevant databases, parameters, and variables for the binary logit model are discussed in Section 4. Section 5 presents sample results in table and map formats. Conclusions and future research improvements to the model are included in Section 6.

\section{Literature Review}

Mode choice analysis in transportation borrows from the traditional consumer utility analysis. The study of mode choice for goods transportation has its root in mode choice analysis in passenger travel demand research. The basic notion of model choice modeling is that the choice of travelers is influenced by and determined through a set of characteristics associated with each mode and the travelers are concerned with maximizing the satisfaction from a choice for a certain set of alternatives. Selected research in this line can be found in [10-22].

Two types of models are common in freight model choice literature: aggregate and disaggregate. An aggregate choice model in freight transportation describes the group behavior of many shippers and carriers. Aggregate choice models typically rely on level-of-service attributes (i.e., price, cost, origin, and destination) for a sample of population [15,23]. An aggregate choice model is useful for describing general trends and policy makers who are interested in decision-making based on general characteristics observed.

A disaggregate choice model describes the behavior of one or a small number of shippers/carriers who have the same relative shipping characteristics. For freight transportation, the disaggregated choice models take the form of consignment or logistics models. The consignment models take into account the characteristics of the commodity and alternative modes [24], such as cost, time, weight, value, distance, reliability [23]. The logistics choice models take into account inventory and supply chain information, such as inventory costs, loss and damage costs, capital carrying costs, shipping rates, and reliability of modal service [25].

The most popular discrete choice models include probit and logit models, which can be binary, multinomial, and nested multinomial [17], with the discrete logit model being the dominant one in transportation research. [10] was the first to use the multinomial logit model in theoretical analysis of individual choice behavior and provided a key component to the multinomial logit with the influential independence of irrelevant alternatives (IIA). The logit model was first used in transportation by [26] in describing travel mode choices between auto and transit. The model considers the utility gained from each alternative choice by considering the characteristics of each respective alternative.

In freight transportation, [27] estimated the model choice for each commodity using a binary logit model and provided insights for each commodity's variation in shipment according to its qualities. [28] used a multinomial logit model to estimate the model choice between freight movements in their study of spatial price competition. The study combined model and destination pairs 
such as barges to Portland, trains to Seattle, trains to Portland and truck/barge to Portland. They found that with the expansion of the market boundary, increases in the probability of the mode/destination choice occur. For areas where freight movement is consolidated to only two modes, binary logit for only rail and truck can be used. [29] used a binary logit model for rail and truck flows in the European freight flow model. Their research compared the use of a binary logit to that of a neural network model. Their study suggests that when calibrating a model for changes in attributes of the network and the modes, the binary logit is more sensitive to those changes.

[30] used logit model as part of a model for Texas trade and industrial production. In this study, the demand for commodities was forecasted using an Input-Output model using the multinomial logit for assigning certain freight modes to the network. The multinomial logit was used to model the origin and rail and truck mode choices for Texas counties and export zones to estimate export zone flows, which were assigned to inter-zonal flows. [31] developed the Great Britain Freight Model (GBFM) to integrate multiple data sources and software components into one entity to observe and analyze domestic and international freight flows in Great Britain.

\section{Methodology}

This study utilizes and compares two general models commonly used in transportation, namely binary logit model and regression model, to investigate the relative contributions of important factors to freight flows by truck and rail in the US

\subsection{Binary Logit Model}

The binary logit model is formulated as:

$$
\begin{gathered}
P_{i j}=f\left(U_{i j}\right) \\
U_{i j}=V_{i j}+\varepsilon_{i j}
\end{gathered}
$$

where $P_{i j}=$ probability that decision maker (i.e., shipper or carrier) $i$ chooses mode $j(j=t$ or $r$, truck $=t$ and rail $=$ $r$ ); $U_{i j}=$ utility function; $V_{i j}=$ the observable portion of the utility; and $\varepsilon_{i j}=$ random portion of the utility.

Following [15] and dropping the random portion in Equation (2), we can write the binary logit model as:

$$
P_{i j}=e^{V_{i j}} / \sum_{j=r, t} e^{V_{i j}}
$$

where $\sum_{j=r, t} P_{i j}=1.0$.

This study concerns the aggregate freight movement (the total flows for a commodity from an origin to a destination from all individual decision makers) in US and thus is not interested in differences among decision mak- ers who may view the same contributing factors differently in model choice due to the decision makers' own constraints and opportunities. Rather, we assume these decision makers are represented by one rational decision maker who must choose between truck or rail mode in shipping throughout US In this case, we can drop the $i$ in Equations (1)-(3) above and only consider the mode relevant factors, such as those related to the commodity, the network, the cost that faces the decision maker.

The observable portion of the utility function must be specified to be operational. Following the convention in literature, we can write the observable utility in an addictive form for $V_{i t}$ and $V_{i r}$ as follows (after dropping $i$ ):

$$
\begin{aligned}
& V_{t}\left(x_{l t}, y_{m t}, z_{n t}\right)=\beta_{t}+\sum_{l=1}^{l} a_{l} x_{l t}+\sum_{m=1}^{m} b_{m} y_{m t}+\sum_{n=1}^{n} c_{n} z_{n t} \\
& V_{r}\left(x_{l r}, y_{m r}, z_{n r}\right)=\beta_{r}+\sum_{l=1}^{l} a_{l} x_{l r}+\sum_{m=1}^{m} b_{m} y_{m r}+\sum_{n=1}^{n} c_{n} z_{n r}
\end{aligned}
$$

The input $x_{l t}\left(x_{1 t}, \cdots, x_{l t}\right), x_{l r}\left(x_{1 r}, \cdots, x_{l r}\right)=$ commodity-relevant observable input of truck or rail mode (i.e., weight, value); $y_{m t}\left(y_{1 t}, \cdots, y_{m t}\right), y_{m r}\left(y_{1 r}, \cdots, y_{m r}\right)=$ network-relevant observable input of truck and rail mode (i.e., O-D distance, speed); $z_{n t}\left(z_{1 t}, \cdots, z_{n t}\right), z_{n r}\left(z_{1 r}, \cdots, z_{n r}\right)=$ decision maker-relevant observable input (i.e., fuel cost). $l, m$, and $n$ are numbers of variables. In the above, $a_{l}, b_{m}, c_{n}$ are parameters to be estimated and $\beta_{t}, \beta_{r}$ are mode specific constants.

The independence of irrelative alternatives (IIA) property applies to the binary logit model in that the relative probability of choosing $t$ rather than $r$ depends only on the characteristics (utility) of the alternatives $t$ and $r$ [10]. Moreover, as long as $V_{t}$ and $V_{r}$ do not change, the relative probability will not change, regardless of whether other alternatives area added or deleted from the choice set [32]. This can be shown by using Equation (3) for the two modes:

$$
\begin{aligned}
P_{t} / P_{r} & =\left[e^{V_{t}} /\left(e^{V_{t}}+e^{V_{r}}\right)\right] /\left[e^{V_{r}} /\left(e^{V_{t}}+e^{V_{r}}\right)\right] \\
& =e^{V_{t}} / e^{V_{r}}=e^{V_{t}-V_{r}}
\end{aligned}
$$

By taking a natural logarithm transformation, we have:

$$
\begin{aligned}
\ln \left(P_{t} / P_{r}\right) & =\ln \left[P_{t} /\left(1-P_{t}\right)\right] \\
& =V_{t}\left(x_{l t}, y_{m t}, z_{n t}\right)-V_{r}\left(x_{l r}, y_{m r}, z_{n r}\right)
\end{aligned}
$$

or

$$
\begin{aligned}
\ln \left(P_{t} / P_{r}\right) & =\beta_{t}-\beta_{r}+\sum_{l=1}^{l} a_{l}\left(x_{l t}-x_{l r}\right) \\
& +\sum_{m=1}^{m} b_{m}\left(y_{m t}-y_{m r}\right)+\sum_{n=1}^{n} c_{n}\left(z_{n t}-z_{n r}\right)
\end{aligned}
$$

The above model (7) or (8) is in fact logit based odds model, $\ln P_{t} /\left(1-P_{t}\right)$, for choosing truck mode as a function of differences between truck utility function and rail 
utility function. This additive formulation allows the estimation of logit parameters of $a_{l}, b_{m}, c_{n}$ with observed $P_{t}, P_{r}=\left(1-P_{t}\right)$ with inputs $x_{l t}, y_{m t}, z_{n t}$ and $x_{l r}, y_{m r}, z_{n r}$ through logarithmic linear regression. The best-fit log-linear regression function with the constant estimate, $\beta$, the probability estimates, $\hat{P}_{t}, \hat{P}_{r}$, and the parameters, $a_{l}, b_{m}, c_{n}$, can be written as:

$$
\begin{gathered}
\ln \left(\hat{P}_{t}, \hat{P}_{r}\right)=\beta+\sum_{l=1}^{l} a_{l}\left(x_{l t}-x_{l r}\right)+\sum_{m=1}^{m} b_{m}\left(y_{m t}-y_{m r}\right) \\
+\sum_{n=1}^{n} c_{n}\left(z_{n t}-z_{n r}\right) \\
\hat{P}_{t}=\frac{e^{\beta+\sum_{l=1}^{l} a_{l}\left(x_{l t}-x_{l r}\right)+\sum_{m=1}^{m} b_{m}\left(y_{m t}-y_{m r}\right)+\sum_{n=1}^{n} b_{m}\left(z_{n t}-z_{n r}\right)}}{1+e^{\beta+\sum_{l=1}^{l} a_{l}\left(x_{l t}-x_{l r}\right)+\sum_{m=1}^{m} b_{m}\left(y_{m t}-y_{m r}\right)+\sum_{n=1}^{n} b_{m}\left(z_{n t}-z_{n r}\right)}}
\end{gathered}
$$

for each of $k$ O-D pairs.

$$
\hat{P}_{r}=1-\hat{P}_{t}
$$

for each of $k$ O-D pairs.

\subsection{Linear Regression Model}

The linear regression model utilizes the estimation method of ordinary least squares to estimate the parameters for the dataset. The equations take the following forms for truck $t$ and rail $r$ :

$$
\begin{aligned}
& \bar{P}_{t}=\beta_{t}+\sum_{l=1}^{l} a_{l} x_{l t}+\sum_{m=1}^{m} b_{m} y_{m t}+\sum_{n=1}^{n} c_{n} z_{n t}+e_{t}=P_{t}+e_{t} \\
& \bar{P}_{r}=\beta_{r}+\sum_{l=1}^{l} a_{l} x_{l r}+\sum_{m=1}^{m} b_{m} y_{m r}+\sum_{n=1}^{n} c_{n} z_{n r}+e_{r}=P_{r}+e_{r}
\end{aligned}
$$

or

$$
\begin{aligned}
& \tilde{P}_{t}=\bar{P}_{t} /\left(\bar{P}_{t}+\bar{P}_{r}\right), \text { for each of } k \text { O-D pairs } \\
& \tilde{P}_{r}=\bar{P}_{r} /\left(\bar{P}_{t}+\bar{P}_{r}\right) \text {, for each of } k \text { O-D pairs }
\end{aligned}
$$

where $P_{t}$ and $P_{r}=$ the actual proportions of tonnage shipped on each mode $r$ and $t, \bar{P}_{t}$ and $\bar{P}_{r}=$ the regression estimated proportions of tonnage shipped on each mode $r$ and $t, e_{t}$ and $e_{r}=$ errors between actual and estimated for each mode $r$ and $t$. Transformations (14)-(15) are important to ensure $\tilde{P}_{t}+\tilde{P}_{r}=1.0$ since the regression estimated probabilities $\left(\bar{P}_{t}\right.$ and $\left.\bar{P}_{r}\right)$ in Equations (12) and (13) are typically not summed to 1.0.

\subsection{Model Performance Measures}

The relative performance of the binary logit model (9)-(11) and the linear regression model (12)-(15) can be quickly compared using the average absolute changes between estimated and observed probabilities (16)-(23) and correlations shown by scatter plots of observed and estimated probabilities.
Regression model estimates vs. observed probabilities:

$$
\left|\left(\tilde{P}_{t}-P_{t}\right) / P_{t}\right|
$$

absolute change for an O-D pair, truck.

$$
\left|\left(\tilde{P}_{r}-P_{r}\right) / P_{r}\right|
$$

absolute change for an O-D pair, rail.

$$
\sum_{k}\left|\left(\tilde{P}_{t}-P_{t}\right) / P_{t}\right| / k
$$

average absolute change for $k$ O-D pairs, truck .

$$
\sum_{k}\left|\left(\tilde{P}_{r}-P_{r}\right) / P_{r}\right| / k
$$

average absolute change for $k$ O-D pairs, rail.

Binary logit model estimates vs. observed probabilities:

$$
\left|\left(\hat{P}_{t}-P_{t}\right) / P_{t}\right|
$$

absolute change for an O-D pair, truck.

$$
\left|\left(\hat{P}_{r}-P_{r}\right) / P_{r}\right|
$$

absolute change for an O-D pair, rail.

$$
\sum_{k}\left|\left(\hat{P}_{t}-P_{t}\right) / P_{t}\right| / k
$$

average absolute change for $k$ O-D pairs, truck.

$$
\sum_{k}\left|\left(\hat{P}_{r}-P_{r}\right) / P_{r}\right| / k
$$

average absolute change for $k$ O-D pairs, rail.

\section{Database, Parameters, and Variables}

\subsection{Freight Databases}

There are numerous useful freight databases from the private sector (i.e., PIERS) and the public sector, such as Commodity Flow Survey (CFS), Railroad Performance Measures (RPM), and Freight Analysis Framework (FAF). These databases vary by commodity code, such as Standard Classification of Transportation Goods (SCTG), Harmonized Schedule (HS); geographic level, such as country, state, metropolitan statistics area (MSA); time, such as yearly or monthly; mode (i.e., truck, rail), etc. Databases from the private sector are often proprietary and costly, while the databases from the public sector are often aggregated but free.

This study uses Freight Analysis Framework (FAF ${ }^{2.2}$ ) database, which has origin-destination (O-D) information for 43 commodity groups in SCTG, is based on 2002 CFS and projected for 2010 through 2035. The geographic information system (GIS) database includes 131 metropolitan statistic areas (MSA) and the remainders of states. It also contains information on USA domestic 
shipments in value and weight by mode. The latest available $\mathrm{FAF}^{3.0}$ is based on 2007 CFS and projected for 2010 to 2040. However, FAF $^{2.2}$ contains virtually the same information on mode, value, weight, commodity, and O-D pairs as $\mathrm{FAF}^{2.2}$ does.

There are also some highway and rail network databases in a GIS format, such as North American Transportation Atlas Data (NTAD) from the Bureau of Transportation Statistics (BTS), the intermodal highway transportation network by Oak Ridge National Laboratories (ORNL), $\mathrm{FAF}^{2.2}$ highway network in Shape GIS format. This study utilizes the 2006 NTAD truck and rail networks processed within TransCAD 4.8 [33].

The study area and data used for this research are all cereal grains shipments by rail and truck in the US According to BTS, cereal grains freight comprised of approximately $7 \%$ of all freight moved in the US during the year 2002 [34]. The FAF $^{2.2}$ dataset describes the cereal grains commodity according to the SCTG coding scheme. This commodity class includes multiple types of grain including but not exclusive to unsweetened corn, wheat, rye, barley, and oats.

The dataset contains 11 origins and 22 destinations each receiving at least one shipment of cereal grain using truck and rail. For validation of the model choice analysis, only origins and destinations (O-D) which sent and received cereal rain by truck and rail were considered. Other O-Ds which shipped only by truck or only by rail were excluded because of the possibility that a modal choice could not take place. Intermodal choices that may occur somewhere on the route to a destination were not considered in this study. Some outliers (about 10) were also excluded. As a consequence the dataset used as input to the binary logistic model contains about 60 observations.

\subsection{Parameters and Variables}

The parameters consist of both characteristics of the shipment and characteristics of the mode. In general it is helpful to use alternative specific variables. Alternative specific variables are those which vary across modes. However, since the mode specific information is often unavailable, variables which provide generic measurement for all modes are useful. Generic characteristics are those attributes that are indistinguishable between modes. The generic features of the shipment, such as tonnage and value, apply to all modes, though the actual magnitudes of tonnage and value for each shipment may be different [35]. So are the network features, such as travel distance or speed or time, and energy use features, such as fuel consumption.

For this study, variables were chosen to describe two different modes: truck and railroad. For each mode, the generic variables are used to construct the utility function for a mode. The parameters and variables are listed in Table 2.

\subsubsection{Commodity Variables}

The generic characteristics of the commodity shipment take the form of shipment tonnage and dollar value. These measurements for the commodity are given in units of tons and millions of US dollars. The variables are denoted $x_{1 t}, x_{1 r}$ in Table 2.

\subsubsection{Network Variables}

The rail and truck transportation networks are totally different. However, the same set of origins and destinations for cereal grains are used for both networks. Origins and destinations were connected to each network. The attribute file for the railroad and highway network provides the length of each link in the network. TransCAD's multiple shortest path function was used to compute the shortest path distance for each origin and destination. O-D shortest path distances were recorded for both networks. The speed values include the stop times for trucks and the dwell times for rail shipments. The speed values for railroads were taken from the Railroad Performance Measures dataset [36]. Their dataset is a compilation of US railroad information including average speeds and average dwell times for railroad destinations. The truck speeds were taken from a study conducted by the American Transportation Research Institute [37]. The travel time is calculated by distance for each O-D divided by the speed of the mode for the O-D pair. The variables are denoted $y_{1 t}, y_{1 r}$ in Table 2.

\subsubsection{Fuel Cost Variable}

Estimating the cost of freight transportation is a challenging task and there is much difficulty in determining all the costs which contribute to the overall cost of freight movement precisely. The following formula (24)

Table 2. Parameters and variables used in the binary logit model.

\begin{tabular}{cclc}
\hline Parameter & Variable & \multicolumn{1}{c}{ Description } & Type \\
\hline$\beta$ & & $\begin{array}{l}\text { Regression constant } \\
\text { Weight in tons of } \\
a_{1}\end{array}$ & Constant \\
$a_{2}$ & $x_{1 t}, x_{1 r}, x_{2 r}$ & $\begin{array}{l}\text { G shipment } \\
\text { Value in dollars of } \\
\text { a shipment } \\
\text { Shortest network } \\
\text { distance for an O-D pair }\end{array}$ & Generic \\
$b_{1}$ & $y_{1 t}, y_{1 r}$ & $\begin{array}{l}\text { Travel time = distance/ } \\
\text { speed }\end{array}$ & Generic \\
$b_{2}$ & $y_{2 t}, y_{2 r}$ & Fuel cost per ton-mile of \\
a shipment & Generic \\
\hline$c_{1}$ & $z_{1 t}, z_{1 r}$ & &
\end{tabular}


was used for estimating the cost of fuel for cereal grains shipments.

$$
F_{j}=\left(r_{j} / b\right) \theta
$$

where $j=$ mode; $r_{j}=$ British thermal units (BTU) per ton-mile (measured as the total BTU consumed for that year for the mode divided by the total ton-miles for the mode $)^{1} ; b=$ Number of BTU's equal to one gallon of fuel $(138,700)^{2} ; \quad \theta=$ Fuel cost (\$/gallon) per gallon ${ }^{2} ; F_{j}=$ Fuel cost per ton-mile mode $j$.

This measurement was originally used for the purpose of comparing the use of fuel in freight transportation among modes and their relative energy efficiency [38]. This is done by taking the total amount of fuel consumed in BTU's for the mode in the year 2002 and dividing this by the total amount of ton-miles for the mode in the year 2002. The cost of fuel per gallon was averaged for the year 2002 for both railroad and highway [2]. These calculations provided an estimate for the fuel cost in gallons per ton-mile for each mode. The variables are denoted in Table 2.

Calculations for truck and railroad fuel cost are based on the following 2002 data in Table 3. Rail Fuel Cost per ton-mile $=520320.9831$ billion $/ 1,261,813$ million = 412.36 BTU's per ton-mile. 412.36/138,700 $=0.00297$ gallons of fuel per ton-mile. Similarly, Truck Fuel Cost per ton-mile $=5,104,160$ billion $/ 1,360,760$ million $=$ 3750.96 BTU's per ton-mile. 3750.96/138,700 $=0.027$ gallons of fuel per ton-mile. Here, 138,700 = Amount of British Thermal Units equal to one gallon of diesel fuel.

A sample of the data input to the binary logit model is listed in Table 4. Here the origins and destinations are based on state MSAs and state reminders (rem). Commodity type is cereal grains, including Wheat, Barley, Oats, Corn, etc. The unit for shipment value is million dollars, for time hours, for fuel dollar per ton-mile, and for distance mile.

\section{Results and Analysis}

The binary logit model was tested in TransCAD 4.8. [33].

Table 3. US truck and rail ton-miles, btus, and fuel consumption in 2002.

\begin{tabular}{cccc}
\hline Mode & $\begin{array}{c}\text { Ton-Miles in } \\
\text { 2002 in } \\
\text { millions }\end{array}$ & $\begin{array}{c}\text { BTU consumed } \\
\text { in 2002 in } \\
\text { trillions }\end{array}$ & $\begin{array}{c}\text { Gallons of fuel } \\
\text { used in 2002 in } \\
\text { millions }\end{array}$ \\
\hline Rail & $1,261,813$ & 520 & 3751.413 \\
Truck & $1,360,760$ & 5104 & 36,800 \\
\hline
\end{tabular}

Source: [39] and [2]

Table 4. A sample data input to the binary logit model.

\begin{tabular}{|c|c|c|c|c|c|c|c|c|}
\hline Origin & Destination & Commodity & Mode & Tons & Dollar & Time & Fuel Cost/TM & Distance \\
\hline IL rem & IN rem & Cereal grains & Truck & 220,940 & 14.4 & 4.54 & 0.02700 & 223.0 \\
\hline IL rem & OH rem & Cereal grains & Truck & 2800 & 0.14 & 9.46 & 0.02700 & 464.3 \\
\hline IN rem & IL rem & Cereal grains & Truck & 354,090 & 18.13 & 4.54 & 0.02700 & 223.0 \\
\hline IN rem & IL St Lo & Cereal grains & Truck & 7620 & 0.38 & 4.81 & 0.02700 & 236.0 \\
\hline IN rem & KY rem & Cereal grains & Truck & 465,660 & 23.49 & 3.12 & 0.02700 & 153.3 \\
\hline IN rem & PA rem & Cereal grains & Truck & 14,910 & 1.64 & 11.84 & 0.02700 & 581.4 \\
\hline IN rem & VA rem & Cereal grains & Truck & 18,220 & 1.09 & 9.20 & 0.02700 & 451.9 \\
\hline KS Kansa & KS rem & Cereal grains & Truck & $1,496,610$ & 179.54 & 4.18 & 0.02700 & 205.4 \\
\hline KS Kansa & MO Kansa & Cereal grains & Truck & $3,600,390$ & 185.07 & 1.04 & 0.02700 & 51.1 \\
\hline KS Kansa & TX Dalla & Cereal grains & Truck & 31,820 & 11.85 & 9.61 & 0.02700 & 471.8 \\
\hline$\cdots$ & $\cdots$ & $\cdots$ & $\cdots$ & $\cdots$ & $\cdots$ & $\cdots$ & $\cdots$ & $\cdots$ \\
\hline IL rem & OH rem & Cereal grains & Rail & 35,740 & 3.84 & 24.06 & 0.00297 & 493.2 \\
\hline IN rem & IL rem & Cereal grains & Rail & $2,470,530$ & 64.04 & 12.94585 & 0.00297 & 265.4 \\
\hline IN rem & IL St Lo & Cereal grains & Rail & 128,910 & 3.55 & 2.67561 & 0.00297 & 54.9 \\
\hline IN rem & KY rem & Cereal grains & Rail & 91,450 & 31.57 & 7.149756 & 0.00297 & 146.6 \\
\hline IN rem & PA rem & Cereal grains & Rail & 310,500 & 33.09 & 32.16976 & 0.00297 & 659.5 \\
\hline IN rem & VA rem & Cereal grains & Rail & 194,410 & 108.14 & 25.88878 & 0.00297 & 530.7 \\
\hline KS Kansa & KS rem & Cereal grains & Rail & 44,860 & 11.24 & 9.596098 & 0.00297 & 196.7 \\
\hline KS Kansa & MO Kansa & Cereal grains & Rail & 266,870 & 21.09 & 3.368293 & 0.00297 & 69.1 \\
\hline$\ldots$ & $\ldots$ & $\ldots$ & $\ldots$ & $\ldots$ & $\ldots$ & $\ldots$ & $\ldots$ & $\ldots$ \\
\hline
\end{tabular}

${ }^{1}$ The computation for British thermal units per ton-mile was confirmed by Eastman (1981).

${ }^{2}$ These measurements were given in the Transportation Energy Data Book [39]. 
Two sample screen shots are shown in Figures 1 and 2.

The observed mode split probabilities and the probabilities estimated from the binary logit model for rail and truck are listed in Tables $\mathbf{5}$ and $\mathbf{6}$. It is interesting to see that some observed ( $P_{t}, P_{r}=$ observed probabilities) and estimated probabilities $\left(\hat{P}_{t}, \hat{P}_{r}=\right.$ probabilities from the logit model, $\tilde{P}_{t}, \tilde{P}_{r}=$ probabilities from the regression model) are very close for some O-D pairs for the truck mode, such as OD28, OD27, and OD20 ( $P_{t}=0.52$, $\left.\hat{P}_{t}=0.56, \tilde{P}_{t}=0.52\right)$, but are quite off for OD21, OD12, and OD1 $\left(P_{t}=0.09, \hat{P}_{t}=0.47, \tilde{P}_{t}=0.47\right)$, while most other O-D pairs, such as OD30, OD16, and OD2 ( $P_{t}=$ $\left.0.93, \hat{P}_{t}=0.73, \tilde{P}_{t}=0.58\right)$ are neither too much close or off. Similar results can be found for the rail mode.

Interestingly, some O-D pairs with relatively good logit and regression results for one mode are not necessarily good for the other mode, such as OD22 for truck $\left(P_{t}=0.98, \hat{P}_{t}=0.71, \tilde{P}_{t}=0.55\right)$ and OD22 for rail $\left(P_{r}=0.02, \hat{P}_{r}=0.29, \tilde{P}_{r}=0.45\right)$, while certain O-D pairs are relative good for both models, such as OD23. It seems that for the O-D pairs with extremely unbalanced mode splits, such as $90 \%$ to $10 \%$ rail to truck or vice versa, their logit and regression estimates are relatively worse than those nodes with more balanced modal splits, such as $40 \%$ to $60 \%$ rail to truck or vice versa. Indeed, Tables 5 and 6 both have the last two columns showing the absolute changes between the estimated vs. the observed probabilities. Those O-D pairs with large changes (i.e., larger than 2.0) have their estimates off 3 times more or less than their observed probabilities with some O-D pairs fair better with rail and others with truck. However, the overall averages (1.38 vs. 2.14 for rail and 0.74 vs. 1.75 for truck) indicate that the logit model performs better.

Figures 3-8 illustrate the observed and estimated truck and rail flows assigned to the national truck and rail networks in 2002. In these figures, the truck or rail links/paths with assigned cereal grains flows are highlighted and scaled in back color. The highway and rail segments without carrying cereal grains flows are shown in gray color. These figures are referenced with state boundaries.

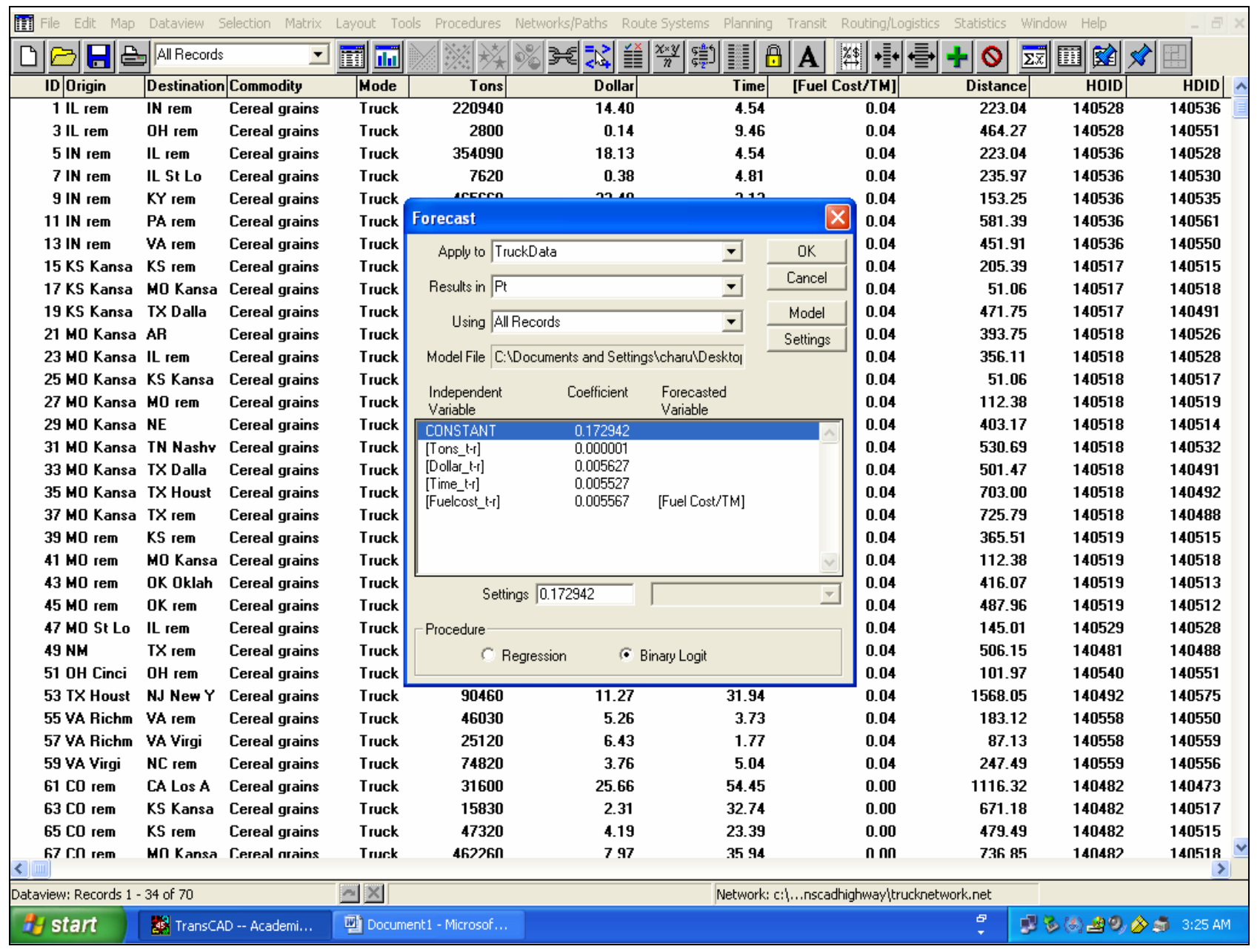

Figure 1. A sample of input data screen. 


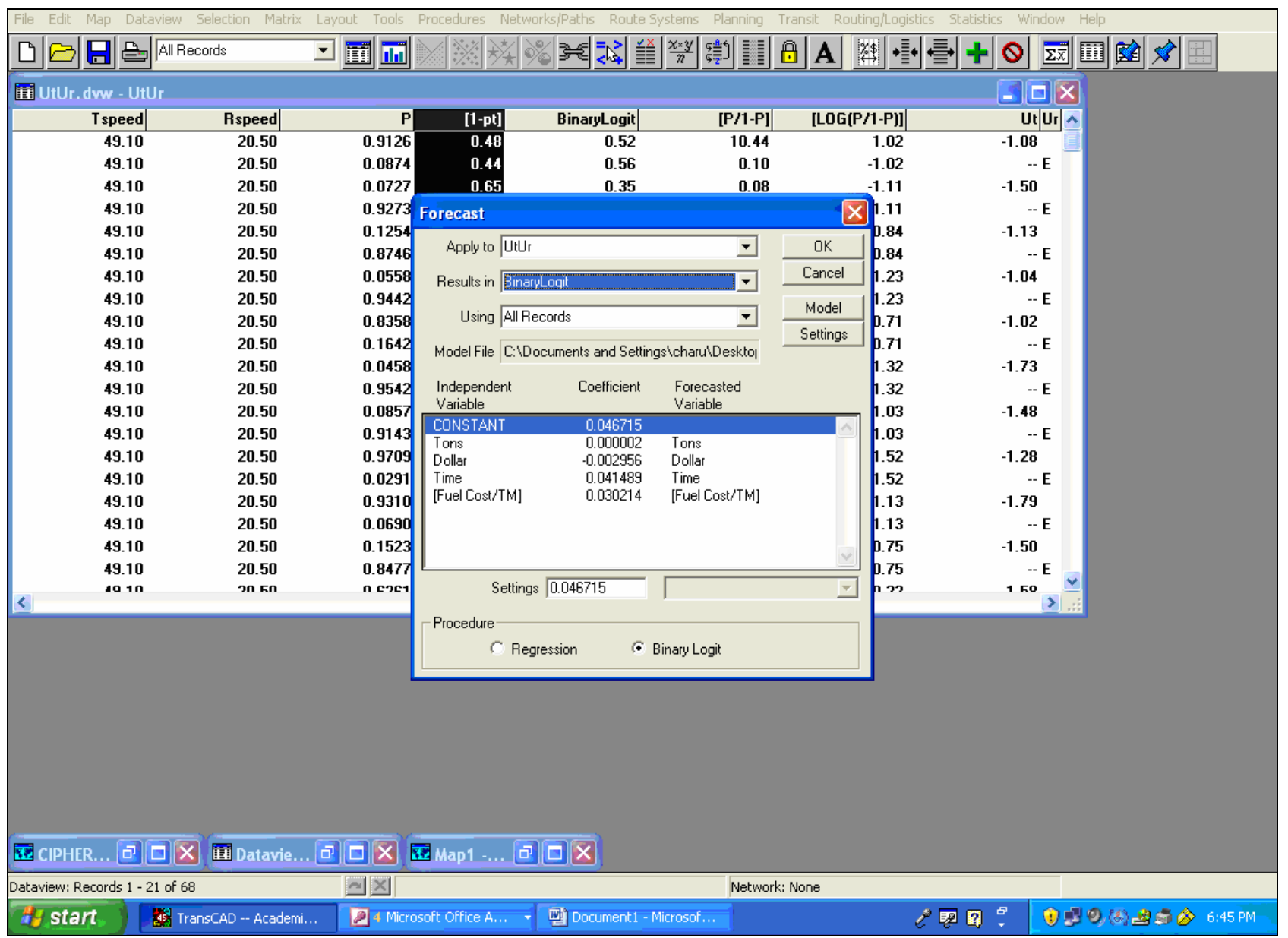

Figure 2. A sample of output probability screen.

As visually shown in these figures, the cereal grains movement spread out within the US, but more concentrated in the middle of US or America's plain region centered around Kansas from which cereal grains were moved to north-south and east-west in the US Comparing these figures and checking the observed and estimated mode splits in Tables $\mathbf{5}$ and $\mathbf{6}$ also show that overall both binary logit model and linear regression estimates work well with just the usage of few generic variables. However, the binary logit model performs better, as shown in Figures 9 and 10, that binary logit model estimates (green color) are more in line with the values and variations of actual percentages or probabilities (black color) than the regression estimates (brown color) for the two modes for cereal grains movement in the US Regression estimates are generally less fluctuated among the origin and destinations pairs

Scatter plots of Figures $\mathbf{1 1}$ and $\mathbf{1 2}$ of actual mode splits vs. logit or regression estimates further indicate that the logit model (green color), with higher R-square or correlation values, generally outperforms the regression model (brown color).

\section{Conclusions and Remarks}

This paper concisely reviewed relevant literature on mode splits for freight movement, developed a binary logit model for truck and rail, tested the model for cereal grains movement in the United States in 2002 using TransCAD, and compared the model results with those from a comparable linear regression model. The overall probability estimates from the binary logit model and the regression model, as compared with the observed mode splits of truck and rail, are better for some O-D pairs than others. However, the logit model outperforms the linear regression model in general in terms of smaller average absolute percentage changes and better correlations between estimated and observed mode probabilities.

The binary logit model also can be applied to other commodities as long as they are transported predominantly by two modes, such as rail and water or truck and water. The input data are at the levels of state MSAs and reminders, but better results, particularly for flow assignments, can be achieved if finer geographic units, such as traffic analysis zones, are used. A specific index may be designed to measure the aggregated deviations 
Table 5. Sample observed and estimated probabilities for rail, 2002.

\begin{tabular}{|c|c|c|c|c|c|}
\hline OD & $P_{r}$ & $\hat{P}_{r}$ & $\tilde{P}_{r}$ & $\left|\frac{\hat{P}_{r}-P_{r}}{P_{r}}\right|$ & $\frac{\hat{P}_{r}-P_{r}}{P_{r}}$ \\
\hline OD1 & 0.91 & 0.53 & 0.53 & 0.42 & 0.42 \\
\hline OD2 & 0.07 & 0.27 & 0.42 & 2.86 & 5.01 \\
\hline OD3 & 0.13 & 0.62 & 0.59 & 3.77 & 3.54 \\
\hline OD4 & 0.06 & 0.39 & 0.59 & 5.50 & 80.87 \\
\hline OD5 & 0.84 & 0.72 & 0.61 & 0.14 & 0.27 \\
\hline OD6 & 0.05 & 0.22 & 0.37 & 3.40 & 6.36 \\
\hline OD7 & 0.09 & 0.28 & 0.49 & 2.11 & 4.48 \\
\hline OD8 & 0.97 & 0.94 & 0.60 & 0.03 & 0.38 \\
\hline OD9 & 0.93 & 0.99 & 0.68 & 0.06 & 0.27 \\
\hline OD10 & 0.15 & 0.26 & 0.44 & 0.73 & 1.90 \\
\hline OD11 & 0.63 & 0.73 & 0.46 & 0.16 & 0.27 \\
\hline OD12 & 0.89 & 0.57 & 0.48 & 0.36 & 0.46 \\
\hline OD13 & 0.87 & 0.99 & 0.70 & 0.14 & 0.19 \\
\hline OD14 & 0.94 & 0.86 & 0.60 & 0.09 & 0.36 \\
\hline OD15 & 0.59 & 0.77 & 0.51 & 0.31 & 0.14 \\
\hline OD16 & 0.64 & 0.41 & 0.40 & 0.36 & 0.38 \\
\hline OD17 & 0.45 & 0.77 & 0.54 & 0.71 & 0.21 \\
\hline OD18 & 0.51 & 0.23 & 0.34 & 0.55 & 0.34 \\
\hline OD19 & 0.53 & 0.6 & 0.33 & 0.13 & 0.39 \\
\hline OD20 & 0.48 & 0.44 & 0.48 & 0.08 & 0.00 \\
\hline OD21 & 0.85 & 0.57 & 0.59 & 0.33 & 0.31 \\
\hline OD22 & 0.02 & 0.29 & 0.45 & 13.5 & 21.35 \\
\hline OD23 & 0.25 & 0.29 & 0.42 & 0.16 & 0.69 \\
\hline OD24 & 0.96 & 0.96 & 0.60 & 0.00 & 0.38 \\
\hline OD25 & 0.74 & 0.45 & 0.43 & 0.39 & 0.42 \\
\hline OD26 & 0.85 & 0.58 & 0.60 & 0.32 & 0.29 \\
\hline OD27 & 0.04 & 0.03 & 0.05 & 0.25 & 0.32 \\
\hline OD28 & 0.5 & 0.44 & 0.55 & 0.12 & 0.11 \\
\hline OD29 & 0.31 & 0.48 & 0.61 & 0.55 & 0.98 \\
\hline OD30 & 0.09 & 0.43 & 0.56 & 3.78 & 5.25 \\
\hline Average & 0.51 & 0.54 & 0.50 & 1.38 & 2.14 \\
\hline
\end{tabular}

Table 6. Sample observed and estimated probabilities for truck, 2002.

\begin{tabular}{|c|c|c|c|c|c|}
\hline OD & $P_{t}$ & $\hat{P}_{t}$ & $\tilde{P}_{t}$ & $\left|\frac{\hat{P}_{t}-P_{t}}{P_{t}}\right|$ & $\frac{\hat{P}_{t}-P_{t}}{P_{t}}$ \\
\hline OD1 & 0.09 & 0.47 & 0.47 & 4.22 & 4.24 \\
\hline OD2 & 0.93 & 0.73 & 0.58 & 0.22 & 0.38 \\
\hline OD3 & 0.87 & 0.38 & 0.41 & 0.56 & 0.53 \\
\hline OD4 & 0.94 & 0.61 & 0.41 & 0.35 & 0.57 \\
\hline OD5 & 0.16 & 0.28 & 0.39 & 0.75 & 1.42 \\
\hline OD6 & 0.95 & 0.78 & 0.63 & 0.18 & 0.33 \\
\hline OD7 & 0.91 & 0.72 & 0.51 & 0.21 & 0.44 \\
\hline OD8 & 0.03 & 0.06 & 0.40 & 1.00 & 12.26 \\
\hline OD9 & 0.07 & 0.01 & 0.32 & 0.86 & 3.55 \\
\hline OD10 & 0.85 & 0.73 & 0.56 & 0.14 & 0.34 \\
\hline OD11 & 0.37 & 0.27 & 0.54 & 0.27 & 0.46 \\
\hline OD12 & 0.11 & 0.43 & 0.52 & 2.91 & 3.75 \\
\hline OD13 & 0.13 & 0.01 & 0.30 & 0.92 & 1.28 \\
\hline OD14 & 0.06 & 0.14 & 0.40 & 1.33 & 5.59 \\
\hline OD15 & 0.41 & 0.23 & 0.49 & 0.44 & 0.21 \\
\hline OD16 & 0.36 & 0.59 & 0.60 & 0.64 & 0.67 \\
\hline OD17 & 0.55 & 0.23 & 0.46 & 0.58 & 0.17 \\
\hline OD18 & 0.49 & 0.77 & 0.66 & 0.57 & 0.35 \\
\hline OD19 & 0.47 & 0.40 & 0.67 & 0.15 & 0.43 \\
\hline OD20 & 0.52 & 0.56 & 0.52 & 0.08 & 0.00 \\
\hline OD21 & 0.15 & 0.43 & 0.41 & 1.87 & 1.75 \\
\hline OD22 & 0.98 & 0.71 & 0.55 & 0.28 & 0.44 \\
\hline OD23 & 0.75 & 0.71 & 0.58 & 0.05 & 0.23 \\
\hline OD24 & 0.04 & 0.04 & 0.40 & 0.00 & 9.06 \\
\hline OD25 & 0.26 & 0.55 & 0.57 & 1.12 & 1.20 \\
\hline OD26 & 0.15 & 0.42 & 0.40 & 1.80 & 1.65 \\
\hline OD27 & 0.96 & 0.97 & 0.95 & 0.01 & 0.01 \\
\hline OD28 & 0.50 & 0.56 & 0.45 & 0.12 & 0.11 \\
\hline OD29 & 0.69 & 0.52 & 0.39 & 0.25 & 0.44 \\
\hline OD30 & 0.91 & 0.56 & 0.44 & 0.38 & 0.52 \\
\hline Average & 0.49 & 0.46 & 0.50 & 0.74 & 1.75 \\
\hline
\end{tabular}




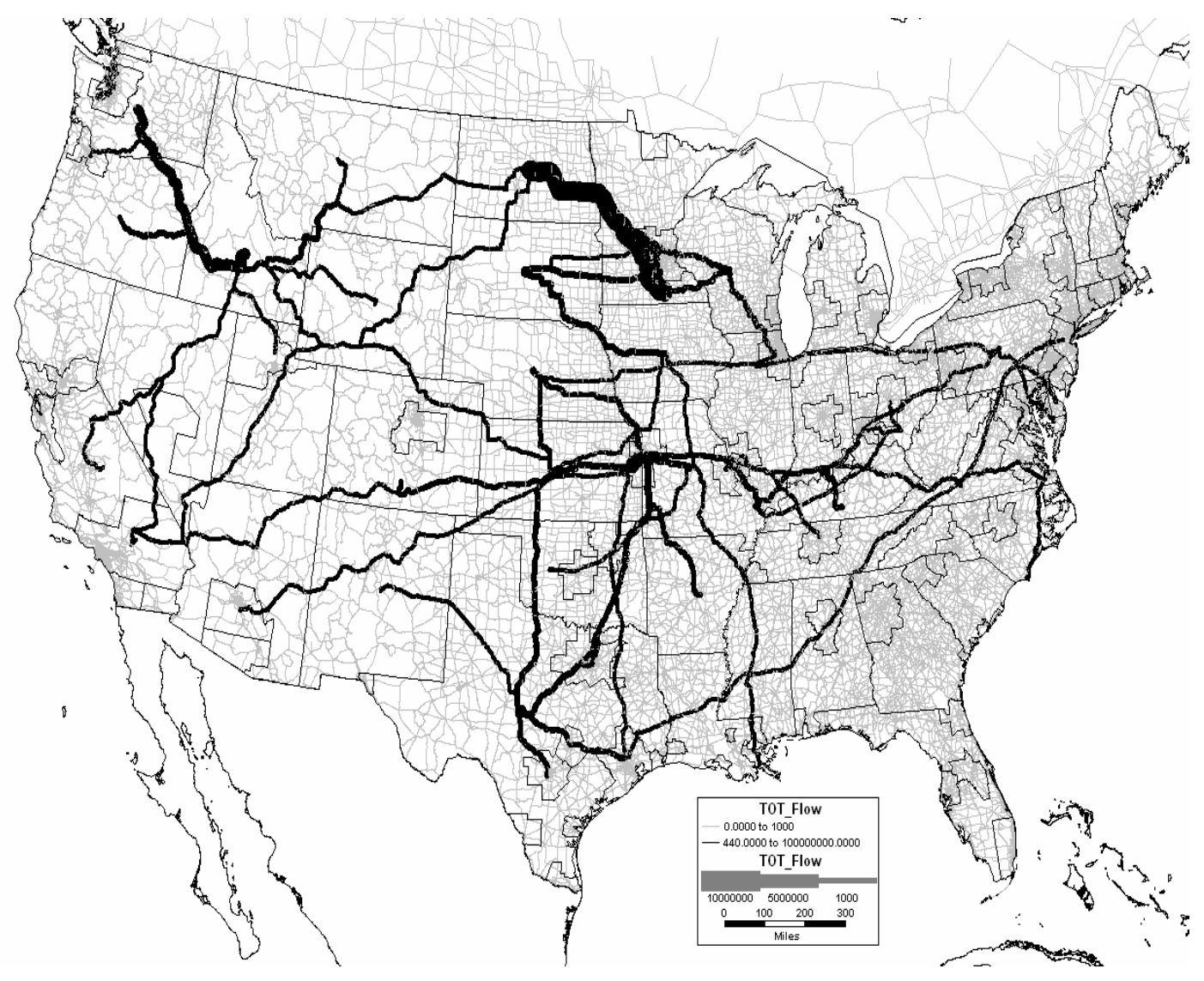

Figure 3. Observed cereal grains flows by truck, 2002.

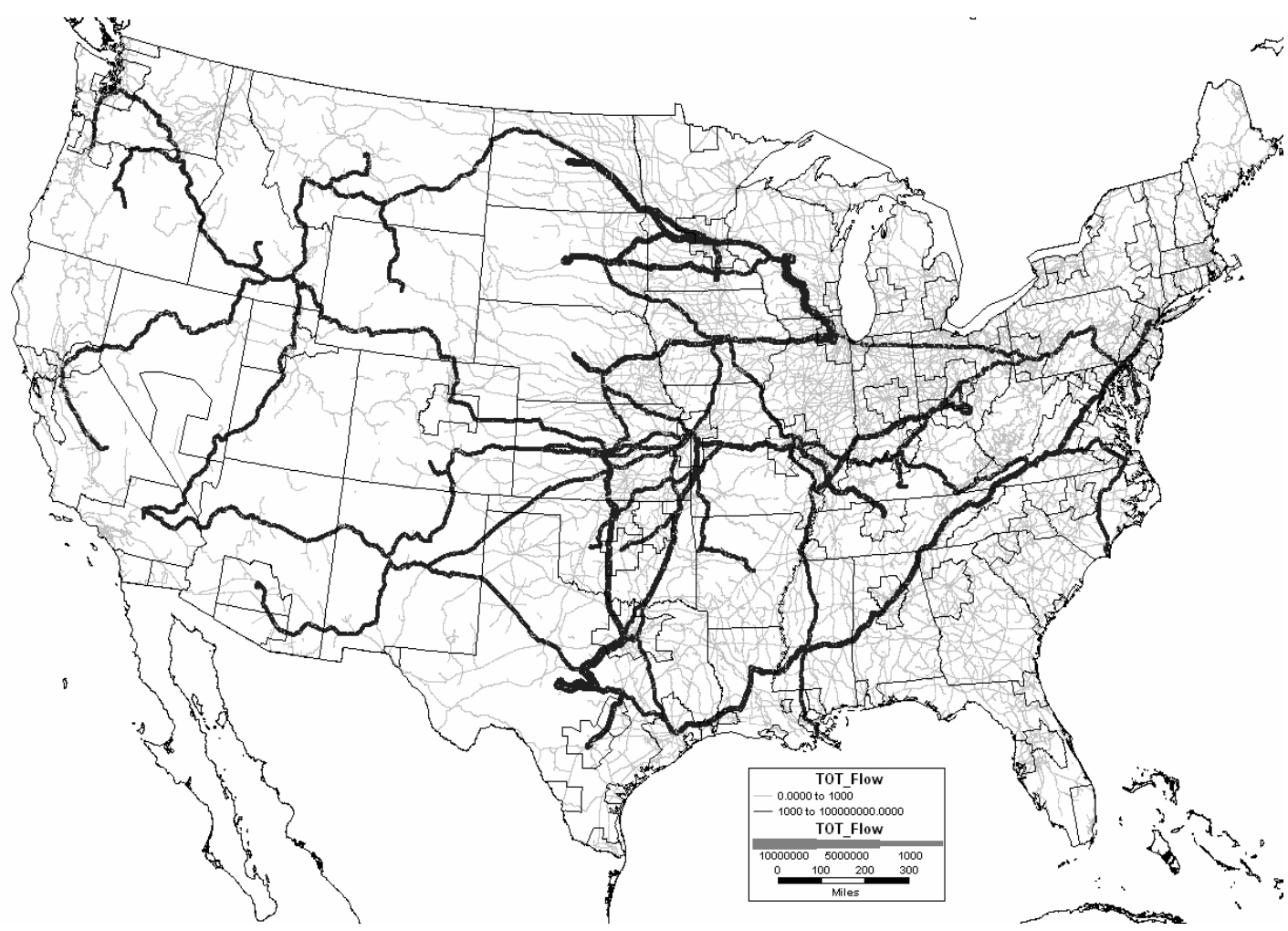

Figure 4. Observed cereal grains flows by rail, 2002. 


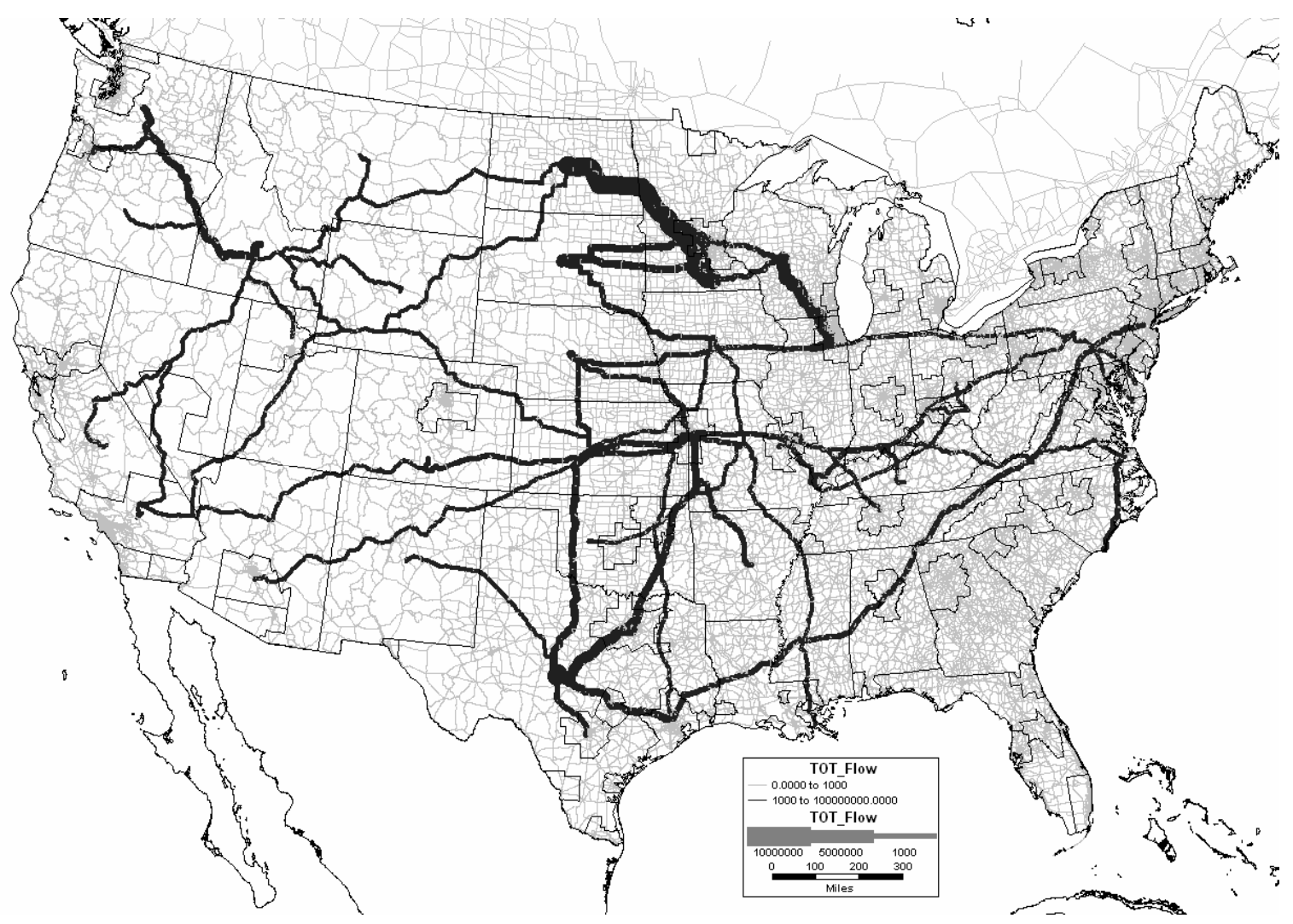

Figure 5. Estimated flows by truck, binary logit model.

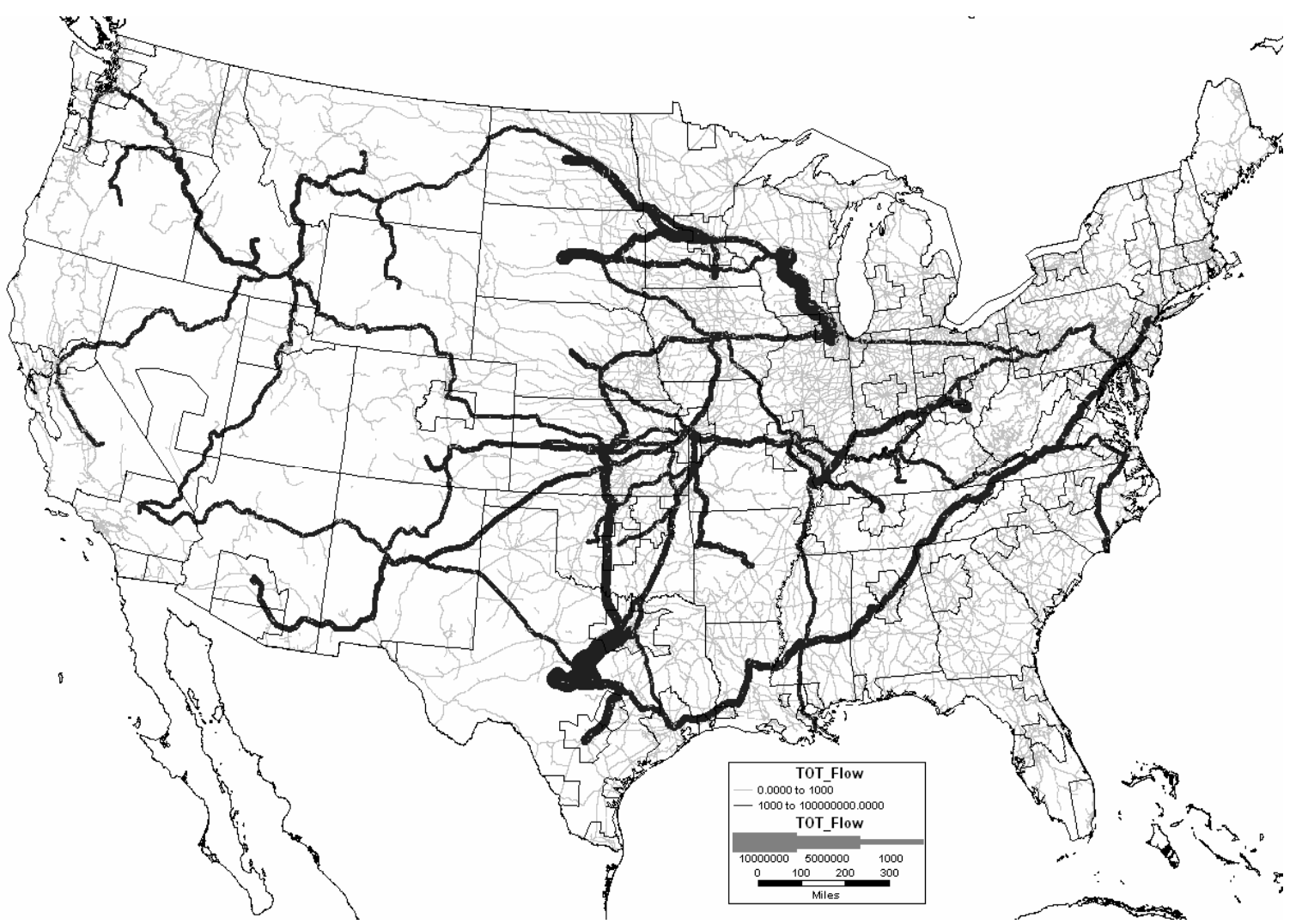

Figure 6. Estimated flows by rail, binary logit model. 


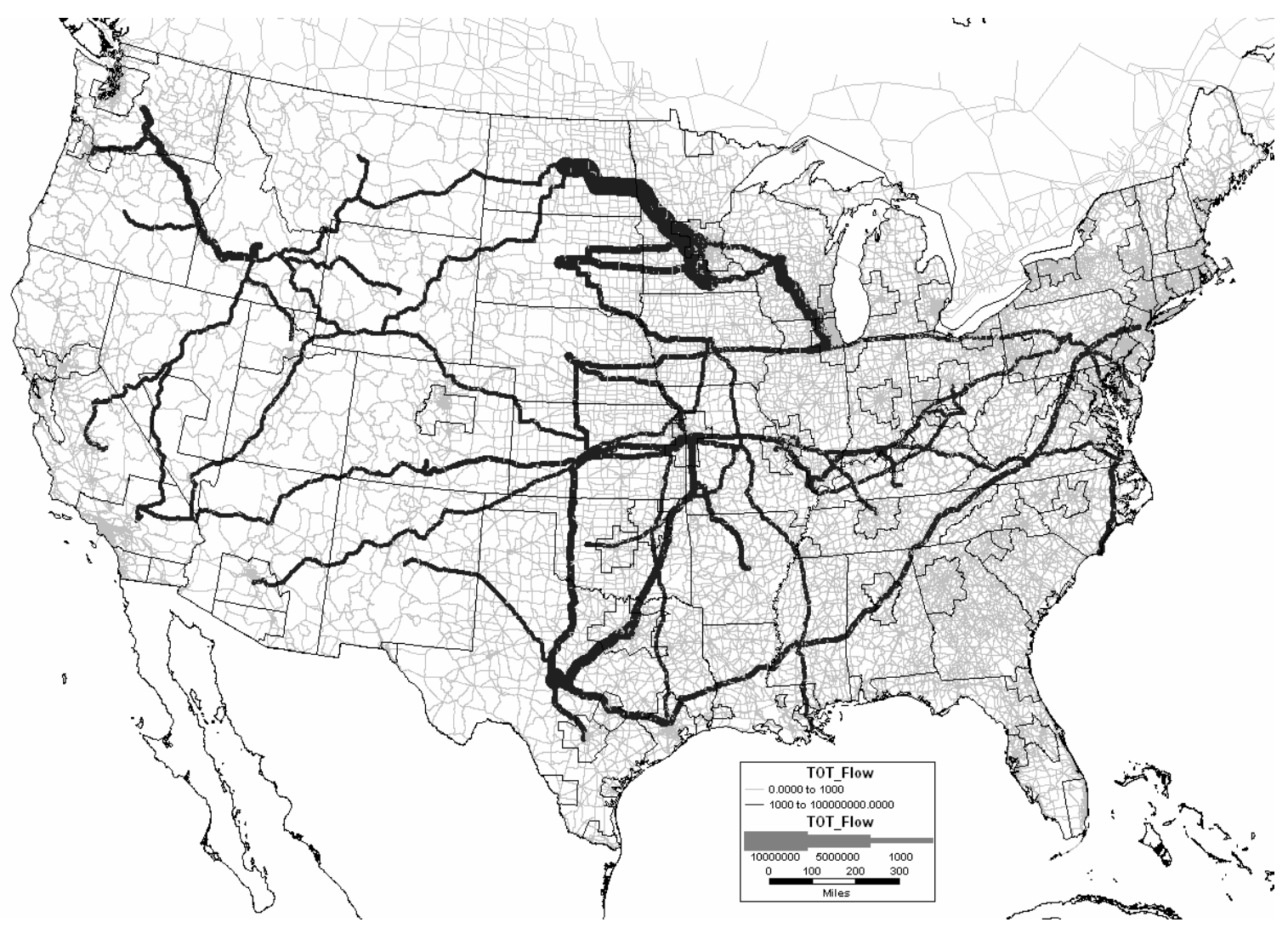

Figure 7. Estimated flows by truck, regression model.

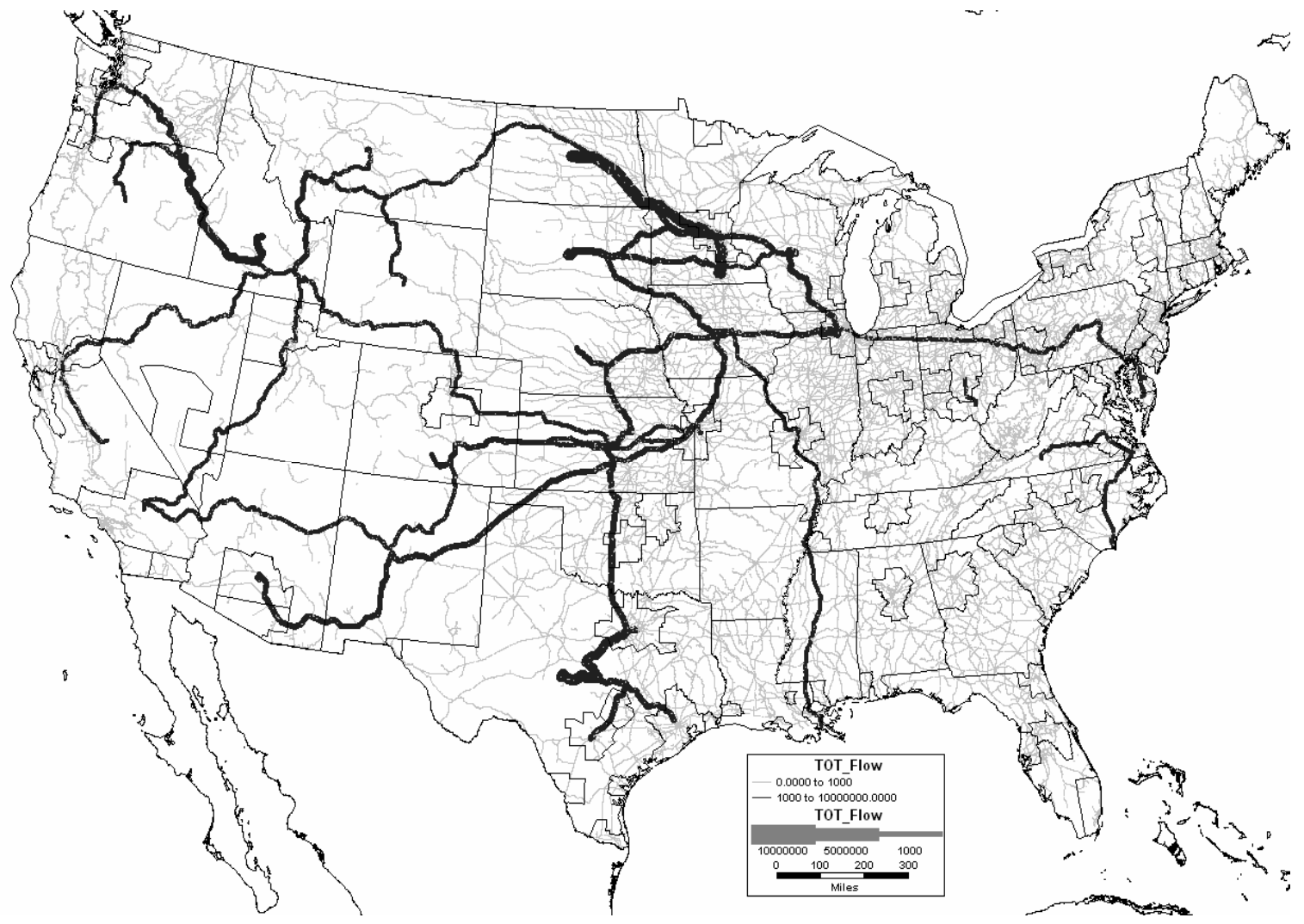

Figure 8. Estimated flows by rail, regression model. 


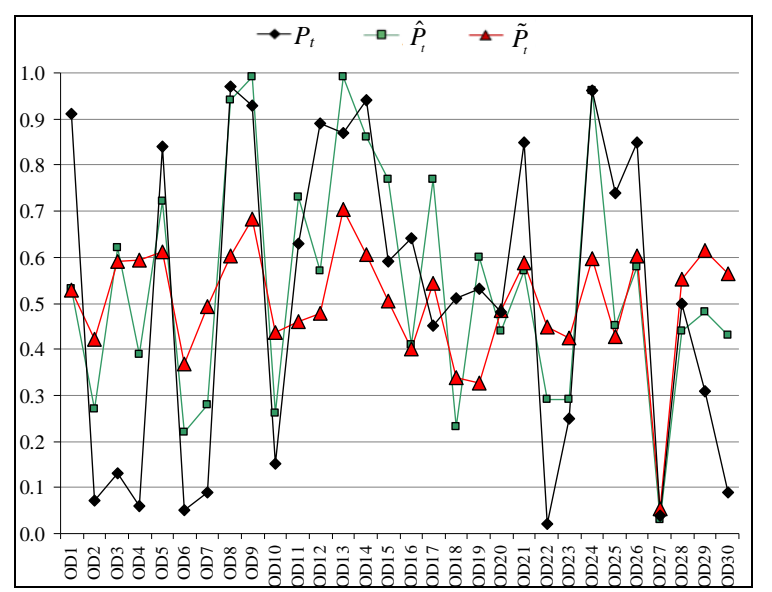

Figure 9. Truck probability comparisions: Actual, binary logit, and regression.

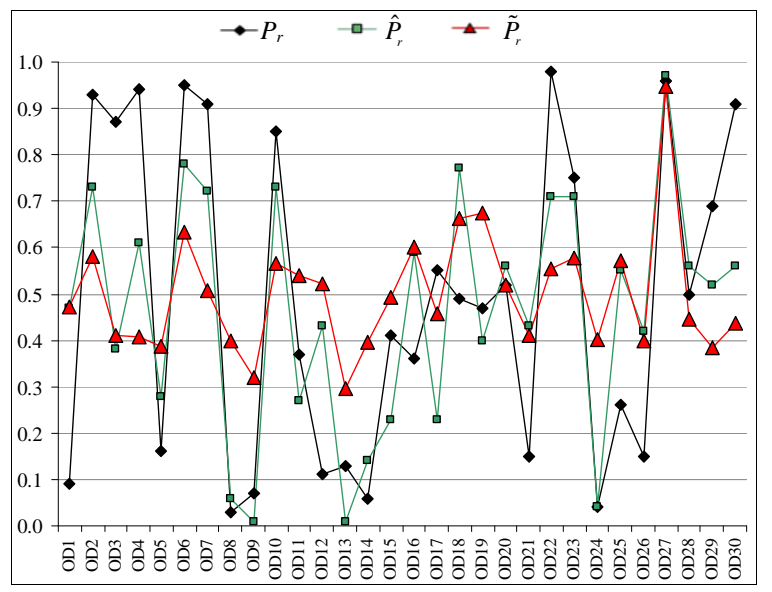

Figure 10. Rail probability comparisions: Actual, binary logit, and regression.

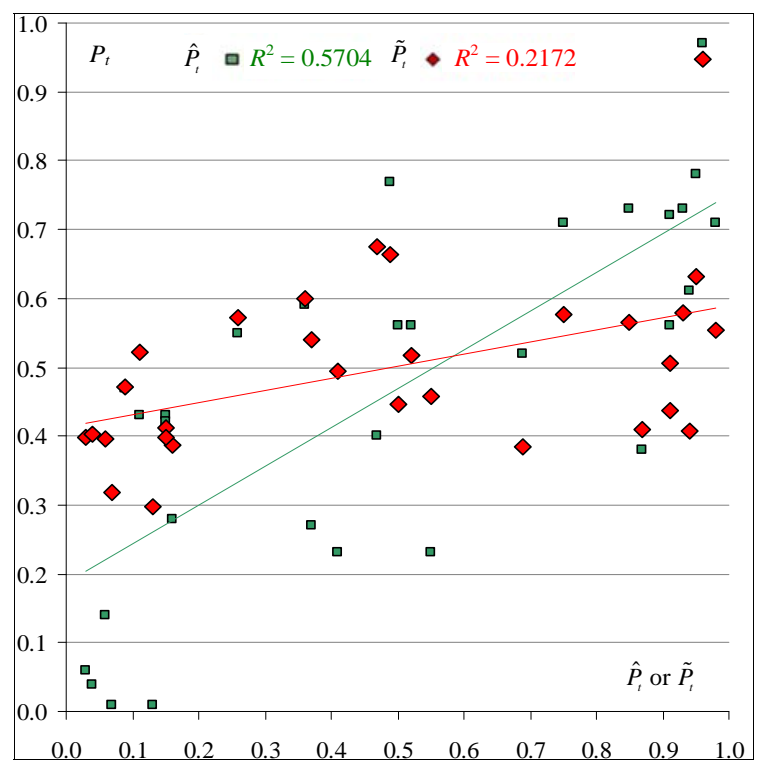

Figure 11. Truck scatter plots of actual vs. logit or regression mode shares.

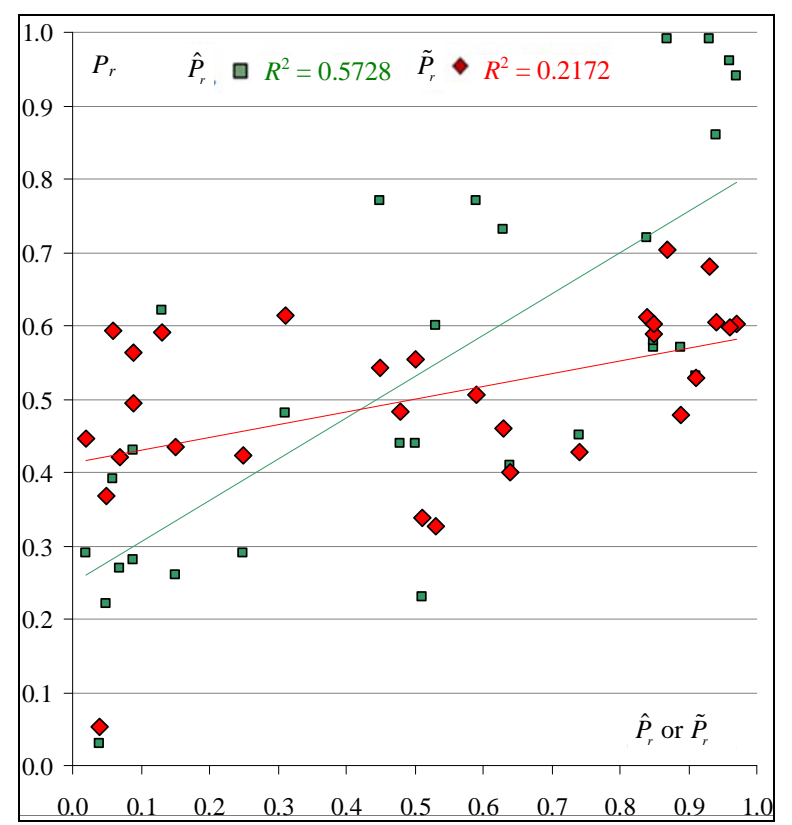

Figure 12. Rail scatter plots of actual vs. logit or regression mode shares.

based on the observed and estimated mode choice probabilities for each mode to further understand the model behaviors. Finally, using more clearly defined generic variables and/or including some mode specific variables will certainly improve the utility of this model for mode share studies in freight transportation planning.

\section{REFERENCES}

[1] US Census Bureau, “Commodity Flow Survey,” 2007. http://www.census.gov/svsd/www/cfsmain.html

[2] Federal Highway Administration, "Fuel Consumption by Transportation Mode: 1980-2005,” 2008.

http://ops.fhwa.dot.gov/freight/freight_analysis/nat_freigh t_stats/docs/07factsfigures/table5_7.htm

[3] Federal Highway Administration, "Freight Analysis Framework," 2009.

http://ops.fhwa.dot.gov/freight/freight_analysis/faf

[4] S. J. Siwek, "Statewide Transportation Planning under ISTEA: A New Framework for Decision Making," Report No. FHWA-PD-96-026A, Washington DC, 1996.

[5] Federal Highway Administration, "Safe, Accountable, Flexible, Efficient Transportation Equity Act: A Legacy for Users,” 2005. http://www.fhwa.dot.gov/safetealu/index.htm

[6] Transportation Research Board, "The Transportation of Grain”, 2008.

http://www.envisionfreight.com/value/pdf/Grain.pdf

[7] United States Department of Agriculture, "Transportation of US Grains: A Modal Share Analysis, 1978-2004,” USDA Agricultural Marketing Services, October 2006.

[8] Cambridge Systematics, "West Coast Corridor Coalition Trade and Transportation Study: Final Report,” Cam- 
bridge Systematics Inc., Cambridge, 2008.

[9] J. Fritelli, "Grain Transport: Modal Trends and Infrastructure Implications,” CRS Report for Congress, 5 January 2005.

[10] R. D. Luce, "Individual Choice Behavior: A Theoretical Analysis,” John Wiley, New York, 1959.

[11] S. L. Warner, "Stochastic Choice of Mode in Urban Travel: A Study in Binary Choice,” 3rd Edition, Northwestern University Press, Evanston, 1962.

[12] D. A. Quarmby, "Choice of Travel Mode for the Journey to Work: Some Findings,” Journal of Transportation Economics and Policy, Vol. 1, No. 2, 1967, pp. 273-314.

[13] R. G. McGillivray, "Binary Choice of Urban Transport Mode in the San Francisco Region,” Econometrica, Vol. 40, No. 5, 1970, pp. 827-848.

[14] A. G. Wilson, "Urban and Regional Models in Geography and Planning,” John Wiley, London, 1974.

[15] T. Domencich and D. McFadden, "Urban Travel Demand: A Behavioral Analysis,” American Elsevier Publishing Company, New York, 1975.

[16] K. Train, "A Structured Logit Model of Auto Ownership and Mode Choice,” Review of Economic Studies, Vol. 47, No. 2, 1980, pp. 357-370. doi:10.2307/2296997

[17] M. E. Ben-Akiva and S. R. Lerman, "Discrete Choice Analysis: Theory and Application to Travel Demand," Master's Thesis, MIT Press, Cambridge, 1985.

[18] B. Bayliss, "The Measurement of Supply and Demand in Freight Transport,” Avebury, Brookfield, 1988.

[19] L. D. Frank and G. Pivo, "Impacts of Mixed use and Density on Utilization of Three Modes of Travel: Single-Occupant Vehicle, Transit, and Walking," Transportation Research Record 1466, Transportation Research Board, Washington DC, 1994, pp. 44-52.

[20] D. Levinson and A. Kumar, "A Multimodal Trip Distribution Model: Structure and Application,” Transportation Research Record 1466, National Research Council, Washington DC, 1995, pp. 124-131.

[21] J. Rajamani, C. Bhat, S. Handy and G. Knaap, “Assessing the Impact of Urban Form Measures in Nonwork Trip Mode Choice after Controlling for Demographic and Level-of-Service Effects,” Transportation Research Board 2003 Annual Meeting Presentation, Washington DC, 2003.

[22] S. Krygsman, "Activity and Travel Choice(s) in Multimodal Public Transport Systems,” Ph.D. Dissertation, Utrecht University, Utrecht, 2004.

[23] E. Cascetta, "Transportation Systems Engineering: Theory and Methods,” Kluwer Academic Publishers, London, 2001.

[24] C. Winston, "The Demand for Freight Transportation: Models and Applications,” Transportation Research, Vol. 17A, No. 6, 1983, pp. 419-427.

[25] P. D. Cook, S. Das, A. Aeppli and C. Martland, "Key
Factors in Road-Rail Model Choice in India: Applying the Logistics Cost Approach,” Simulation Conference Proceedings, Phoenix, 5-8 December 1999, pp. 12801286.

[26] M. Daniel, "Conditional Logit Analysis of Qualitative Choice Behavior,” In: P. Zarembka, Ed., Frontiers in Econometrics, Academic Press, New York, 1973, pp. 105-142.

[27] W. Miklius, K. L. Casavant and P. V. Garrod, "Estimation of Demand for Transportation of Agricultural Commodities," American Journal of Agricultural Economics, Vol. 58, No. 2, 1976, pp. 217-223. doi:10.2307/1238972

[28] F. S. Inada and N. E. Wallace, "Spatial Price Competition and the Demand for Freight Transportation," The Review of Economics and Statistics, Vol. 71, No. 4, 1989, pp. 614-625. doi:10.2307/1928103

[29] A. Reggiani, P. Nijjkamp and L. Nobilio, "Spatial Modal Patterns in European Freight Transport Networks: Results of Neuro-Computing and Logit Models,” Series Research Memoranda No. 0029, Free University Amsterdam, Amsterdam, 1997.

[30] K. Kockelman, L. Lin, Y. Zhao and N. Ruiz-Juri, "Tracking Land Use, Transport, and Industrial Production Using Random-Utility Based Multi-Regional Input-Output Models: Applications for Texas Trade," Transport Geography, Vol. 13, No. 2, 2004, pp. 275-286.

[31] S. Newton and C. Wright, "The GB Freight Model: Methodology,” Draft Paper, MDS Transmodal Ltd., Chester, 2003.

http://www.dft.gov.uk/pgr/economics/ntm/gbfreightmode l.pdf

[32] M. Michael and M. Eric, "Urban Transportation Planning,” Master’s Thesis, Mc Graw Hill, Boston, 2001.

[33] Caliper Corporation, “TransCAD,” 2008. http://www.caliper.com

[34] Bureau of Transportation Statistics, 2007. http://www.bts.gov

[35] C. Winston, "A Disaggregate Model of the Demand for Intercity Freight Transportation,” Econometrica, Vol. 49, No. 4, 1981, pp. 981-1006. doi:10.2307/1912514

[36] “Rail Performance Measures,” 2007. http://www.railroadpm.org

[37] J. Crystal, M. Daniel and S. Jeffery, "Methods of Travel Time Significance in Freight-Significant Corridors,” Transportation Research Board Annual Meeting, Washtington DC, 9-13 January 2005, pp. 1-19.

[38] S. E. Eastman, "Fuel Efficiency in Freight Transportation," Transportation Research Record, 824, Transportation Research Board, Washington DC, 1981, pp. 7-13.

[39] S. C. Davis, S. W. Diegel and R. G. Bounday, "Transportation Energy Data Book,” 28th Edition, Oak Ridge National Laboratory, Oak Ridge, 2006. doi:10.2172/930743 